\title{
Asymptomatic and sub-microscopic malaria infection in Kayah State, eastern Myanmar
}

\author{
Myo Thiha Zaw ${ }^{1,3}$, Myo Thant ${ }^{1}$, Tin Maung Hlaing ${ }^{1}$, Naing Zin Aung ${ }^{1,2}$, Min Thu², Kanit Phumchuea ${ }^{3}$, \\ Kanokwan Phusri ${ }^{3}$, Teerawat Saeseu ${ }^{3}$, Ritthideach Yorsaeng ${ }^{3,4}$, Wang Nguitragool ${ }^{4}$, Ingrid Felger ${ }^{5}$, \\ Jaranit Kaewkungwal ${ }^{6}$, Liwang $\mathrm{Cui}^{7^{*}}$ and Jetsumon Sattabongkot ${ }^{3^{*}}$
}

\begin{abstract}
Background: Myanmar has the heaviest burden of malaria in the Greater Mekong Sub-region. Asymptomatic Plasmodium spp. infections are common in this region and may represent an important reservoir of transmission that must be targeted for malaria elimination.

Methods: A mass blood survey was conducted among 485 individuals from six villages in Kayah State, an area of endemic but low transmission malaria in eastern Myanmar. Malaria infection was screened by rapid diagnostic test $(\mathrm{RDT})$, light microscopy and real-time polymerase chain reaction (PCR), and its association with demographic factors was explored.

Results: The prevalence of asymptomatic Plasmodium spp. infection was $2.3 \%(11 / 485)$ by real-time PCR. Plasmodium vivax accounted for $72.7 \%$ (8/11) and Plasmodium falciparum for $27.3 \%$ (3/11) of infections. Men were at greater risk of infection by Plasmodium spp. than women. Individuals who worked as farmers or wood and bamboo cutters had an increased risk of infection.

Conclusion: A combination of RDT, light microscopy and PCR diagnostics were used to identify asymptomatic malaria infection, providing additional information on asymptomatic cases in addition to the routine statistics on symptomatic cases, so as to determine the true burden of disease in the area. Such information and risk factors can improve malaria risk stratification and guide decision-makers towards better design and delivery of targeted interventions in small villages, representative of Kayah State.
\end{abstract}

Keywords: Asymptomatic, Sub-microscopic, Malaria, Myanmar

\section{Background}

Myanmar has the heaviest burden of malaria among the Greater Mekong Sub-region (GMS) countries. Although the long-term trend showed decreasing malaria morbidity and mortality in Myanmar from 2001 to 2013 [1], there were still 152,195 confirmed malaria cases in 2013, resulting in 92 deaths $[2,3]$. In addition, Myanmar is the

\footnotetext{
*Correspondence: luc2@psu.edu; jetsumon.pra@mahidol.ac.th

${ }^{3}$ Mahidol Vivax Research Unit (MVRU), Faculty of Tropical Medicine, Mahidol University, Bangkok, Thailand

${ }^{7}$ Department of Entomology, The Pennsylvania State University, 501 ASI Building, University Park, PA 16801, USA

Full list of author information is available at the end of the article
}

major source of malaria introduction to its neighboring countries, which impedes progress toward the goal of regional malaria elimination by 2030 . Moreover, with the rise of artemisinin resistance in Plasmodium falciparum, continued political, financial and scientific commitment is required if the ambitious goal of malaria elimination is to be realized [4].

Asymptomatic malaria infections are usually undetectable and rarely treated. As a major source of gametocytes for local mosquito vectors, such infections contribute to the persistence of malaria transmission [5-10]. Significant proportions of asymptomatic infection have been reported in malaria-endemic countries in the GMS 
[11-17]. This means that eliminating this reservoir of Plasmodium parasites in asymptomatic carriers using strategies such as mass drug administration may play a critical role in the elimination of malaria [18].

Despite recent improvement of malaria surveillance in Myanmar, the current data on malaria only represent symptomatic cases, which may be the tip of the iceberg' of the entire infected population. In addition, because symptomatic cases have mostly been detected by microscopy and rapid diagnostic test (RDT), which have limited detection sensitivity, patients with low-density parasitaemia have likely been missed by these surveys. This study aimed to determine the malaria situation in an eastern state of Myanmar, where malaria has been highly endemic in the past. Here a malariometric survey was conducted using microscopy, RDT and real-time polymerase chain reaction (PCR) assays to screen malaria infections in asymptomatic carriers and to explore associated risk factors of residual malaria parasitaemia among local residents.

\section{Methods}

\section{Study sites}

This study was conducted in Kayah State in eastern Myanmar, which borders Mae Hong Son Province in Thailand. Kayah has a tropical climate with average temperatures ranging from $16{ }^{\circ} \mathrm{C}$ in December to $30{ }^{\circ} \mathrm{C}$ in April. The rainy season is from May to late October with annual rainfall of approximately $\sim 3000 \mathrm{~mm}$. Malaria transmission is low, unstable and peaks from May to August, coincident with the rainfalls [19]. There are seven townships in Kayah State, five (Loikaw, Demoso, Hpruso, Mese, Bawlakhe) were chosen for the study (Fig. 1a). One village from each township (two villages in Loikaw Township) was selected to conduct a cross-sectional survey of malaria parasite prevalence.

\section{Data and sample collection}

A community-based, cross-sectional study was conducted to determine the prevalence of asymptomatic Plasmodium spp. infections. The number of participants enrolled was based on the expected prevalence of malaria infection of $10 \%$ in Kayah State, according to the previous study in Myanmar [16]. Participants were recruited by convenience sampling (Fig. 1b). All individuals aged $\geq 6$ months were invited to participate in the survey. Participants were interviewed using a pre-structured questionnaire, to collect general demographic and behavioural information including gender, age, occupation, education level, household size, usage and type of insecticide-treated bed nets, history of previous episodes of malaria, and treatment-seeking behaviour. For participants 5 years or younger, the interview was done with his/ her parents instead. Symptom information was collected and the tympanic temperature measured for each participant. Finger-prick blood samples were used for RDT and

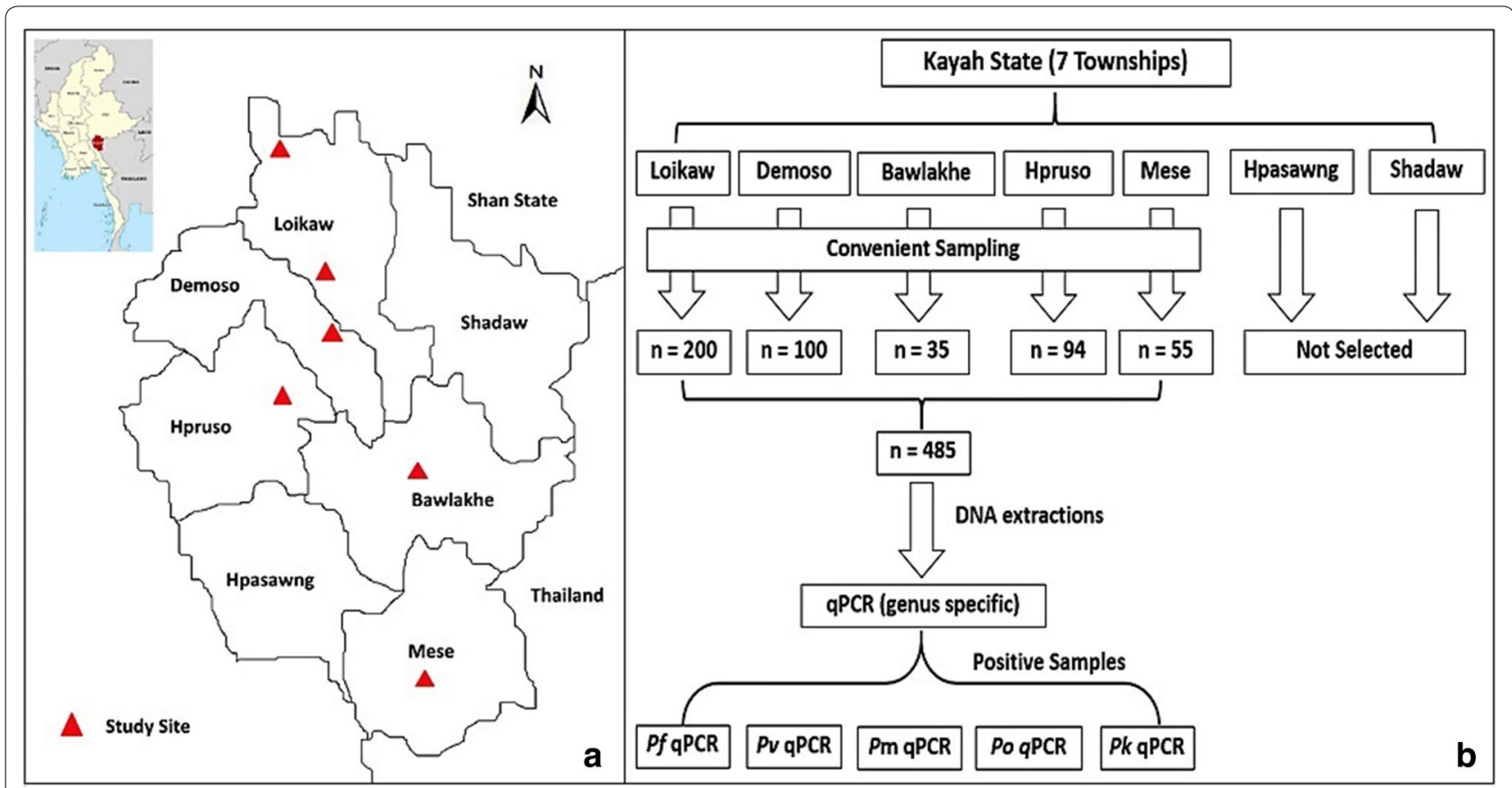

Fig. 1 a Study sites in Kayah State, b steps of research procedure. n, number of samples; Pf, Plasmodium falciparum; Pv, Plasmodium vivax; Pm, Plasmodium malariae; Po, Plasmodium ovale; Pk, Plasmodium knowlesi 
microscopy. In addition, 200-300 $\mu$ l of finger-prick blood from each available participant were collected into EDTA microtainers tubes and stored at $-20{ }^{\circ} \mathrm{C}$ for subsequent molecular parasite detection by PCR.

\section{RDT}

A CareStart ${ }^{\mathrm{TM}}$ Malaria HRP2/pLDH (Pf/PAN) Combo RDT was used to detect Plasmodium species in participant samples. This RDT uses histidine-rich protein 2 (HRP 2) to detect $P$. falciparum and lactose dehydrogenase (LDH) for Plasmodium vivax, Plasmodium ovale and Plasmodium malariae. This RDT has been shown to detect 99 and $94.3 \%$ of test samples with $P$. falciparum and $P$. vivax, respectively, at a density of 200 parasites/ $\mu \mathrm{l}$ of blood and $100 \%$ of test samples with at a density of 2000 parasites/ $\mu \mathrm{l}$ of blood for both species, with 1.5 and $0.7 \%$ false positive rates, respectively [20].

\section{Microscopy}

Thick and thin blood smears were made on the same slide, air dried and transported to the laboratory of the 100-bed hospital in Loikaw Township. The slides were stained with $3 \%$ Giemsa for $10 \mathrm{~min}$ and screened for the presence of plasmodial infections. The slides were read by a local microscopist who was blinded to the individual RDT results. Parasitaemia and gametocytaemia were determined from thick blood films by counting the number of parasites per 200 white blood cells (WBCs). A slide was classified as negative if no Plasmodium asexual forms or gametocytes were found after counting $500 \mathrm{WBCs}$. Thin blood films were examined for Plasmodium species by counting the number of parasites per 5000 red blood cells (RBCs). For quality control purposes, a second experienced microscopist randomly selected $5 \%$ of the slides for re-examination.

\section{PCR}

Whole blood samples, stored at $-20{ }^{\circ} \mathrm{C}$ in microtainers were transferred on dry ice to the laboratory at the Faculty of Tropical Medicine, Mahidol University, Bangkok, Thailand. DNA extraction from 200 to $300 \mu \mathrm{l}$ of each blood sample was carried out using the Favorgen 96-Well Genomic DNA Extraction Kit, following the manufacturer's recommendations. Malaria parasite infection was first identified by the QMAL assay, a genus-specific probe-based quantitative PCR (qPCR) targeting a conserved region of the $18 \mathrm{~S}$ rRNA genes of Plasmodium [21], by using $4 \mu \mathrm{l}$ of purified DNA equivalent to $8 \mu \mathrm{l}$ of whole blood. For positive samples by QMAL, $4 \mu \mathrm{l}$ DNA was subjected to species-specific $18 \mathrm{~S}$ qPCR assays to detect $P$. vivax, $P$. ovale, and $P$. malariae as previously described [22]. For $P$. falciparum, the varATS qPCR assay was used [23]. Plasmodium knowlesi was detected with (forward primer: 5'-GTT AGC GAG AGC CAC AAA AAA GCG AAT- $3^{\prime}$, reverse primer: $5^{\prime}$-ACT CAA AGT AAC AAA ATC TTC CAT A-3', and hydrolysis probe: 5'-HEX-TGC TTT ATG TGC GCA TCC TCT ACC TABFQ-3'). All qPCR assays were performed with $\mathrm{iTaq}^{\mathrm{TM}}$ Universal Probe Supermix $2 \times$ on a CFX 96 real-time PCR detection system.

\section{Statistical analysis}

Data were checked for completeness and consistency, and entered into an SPSS 17.0 (SPSS Inc, Chicago, IL, USA) database. Descriptive statistics and differences in distributions were evaluated using the Chi square $\left(x^{2}\right)$ test. An error probability ( $P$ value) of $<0.05$ was considered statistically significant.

\section{Ethical consideration}

This study was approved by the Institutional Review Board of the Faculty of Tropical Medicine, Mahidol University (MUTM 2016-0140-01) and the Defense Services Medical Research Centre (DSMRC), Myanmar (IRB/2016/31). Written informed consent was obtained from all adults willing to participate in the study, and a parent provided consent for participants under 18 years of age. Malaria-positive participants were treated as per the national treatment guideline.

\section{Results}

\section{Characteristics of the study population}

A total of 485 samples were collected in this study, $54.4 \%$ (264) of which were from male participants. Adolescent and adult participants were predominant and only $8.6 \%(42 / 485)$ were children younger than 10 years old. The median age of participants was 32 years (6 months-65 years). More than $80 \%$ (420) of participants had a primary education or higher. The most frequent occupation among respondents $(49.3 \%, 239)$ was forest-related work (farming, wood and bamboo cutting). More than $70 \%$ of respondents (377) had at least three family members in their household. Nearly all respondents reported using bed nets while sleeping at night and $18.1 \%$ (87) of bed nets used were insecticide treated. The remaining bed nets were ordinary bet nets (Table 1 ).

\section{Prevalence of malaria infection}

The prevalence of malaria infection was detected by RDT, microscopy and qPCR. In this study, infections were considered asymptomatic when a participant's body temperature was $<37.5{ }^{\circ} \mathrm{C}$ at the time of blood collection and a participant reported no fever within the previous 2 days. The prevalence of Plasmodium infection was 1.03\% (5/485; three by $P$. falciparum, one other species and one mixed) by RDT and $1.44 \%(7 / 485)$ by microscopy. Of the 
Table 1 Characteristics of participants

\begin{tabular}{|c|c|c|}
\hline Characteristics & Number & Percent \\
\hline \multicolumn{3}{|l|}{ Sex } \\
\hline Male & 264 & 54.4 \\
\hline Female & 221 & 45.6 \\
\hline \multicolumn{3}{|l|}{ Age (years) } \\
\hline$<5$ & 5 & 1 \\
\hline $5-10$ & 37 & 7.6 \\
\hline $11-20$ & 32 & 6.6 \\
\hline $21-30$ & 138 & 28.5 \\
\hline $31-40$ & 153 & 31.5 \\
\hline$>40$ & 120 & 24.7 \\
\hline Median (range) & 32 years (6 months- 65 years) & \\
\hline \multicolumn{3}{|l|}{ Education } \\
\hline No education & 65 & 13.5 \\
\hline Primary to middle school & 264 & 54.4 \\
\hline High school and above & 156 & 32.1 \\
\hline \multicolumn{3}{|l|}{ Occupation } \\
\hline Forest-related occupation & 239 & 49.3 \\
\hline Students & 54 & 11.1 \\
\hline Housemaker/dependent & 192 & 39.6 \\
\hline \multicolumn{3}{|l|}{ Family size } \\
\hline Less than 3 people & 108 & 22.3 \\
\hline 3-5 people & 334 & 68.9 \\
\hline More than 5 people & 43 & 8.9 \\
\hline \multicolumn{3}{|l|}{ Use of bed nets } \\
\hline Yes & 481 & 99.2 \\
\hline No & 4 & 0.8 \\
\hline \multicolumn{3}{|l|}{ Type of bed nets $(n=481)$} \\
\hline Ordinary bed nets & 394 & 81.9 \\
\hline Insecticide-treated bed nets & 87 & 18.1 \\
\hline
\end{tabular}

seven microscopy-positive samples, five were positive for P. falciparum, one for P. vivax and one for mixed (P. falciparum and $P$. vivax) infections.

Molecular screening by qPCR detected parasite DNA in $2.3 \%(11 / 485)$ of blood samples. Plasmodium falciparum accounted for $27.3 \%$ (3/11) and P. vivax for $72.7 \%$ $(8 / 11)$. No mixed infection was detected by PCR. qPCR confirmed parasite DNA in 100\% of RDT-positive samples and in $85.7 \%(6 / 7)$ of microscopy-positive samples. qPCR detected additional asymptomatic parasitaemia in six RDT-negative samples and five microscopy-negative samples. Plasmodium ovale, $P$. malariae and P. knowlesi were not found in this study.

Only one out of 11 participants with infections presented with fever $>37.5^{\circ} \mathrm{C}$; this was confirmed as $P$. falciparum by PCR. The rest appeared to be healthy with no signs of malaria-like symptoms, including fever, chills and headache.

\section{Demographic characteristics associated with Plasmodium infections}

A significantly higher prevalence of asymptomatic Plasmodium infections was found in males than females. The odds of being asymptomatic were about ten times higher among men than among women. Most qPCR-positive asymptomatic Plasmodium infections were found in adults. Among the positive samples, the youngest participant age was 17 years old. A higher prevalence of asymptomatic Plasmodium species infection was associated with forest-related occupations for malaria infection. Individuals who worked as farmers or wood and bamboo cutters had increased risk of having asymptomatic malaria infection, with an odds ratio approximately ten times greater than participants whose occupation were not forest-related. There were no statistically significant difference in infections by education, family size, or use and types of bed nets (Table 2).

\section{Table 2 Association between characteristics and asympto-} matic malaria infections

\begin{tabular}{|c|c|c|c|c|}
\hline Characteristics & Total & $\begin{array}{l}\text { PCR } \\
\text { Positive (\%) }\end{array}$ & $\begin{array}{l}\text { Odds ratio }(95 \% \\
\mathrm{Cl})\end{array}$ & P value* \\
\hline \multicolumn{5}{|l|}{ Sex } \\
\hline Male & 264 & $10(3.8)$ & $8.67(1.10-68.19)$ & $0.014^{* *}$ \\
\hline Female & 221 & $1(0.5)$ & 1 & \\
\hline \multicolumn{5}{|l|}{ Age (years) } \\
\hline$>20$ & 411 & $10(2.4)$ & $1.82(0.23-14.44)$ & 0.565 \\
\hline$\leq 20$ & 74 & $1(1.4)$ & 1 & \\
\hline \multicolumn{5}{|l|}{ Education } \\
\hline $\begin{array}{l}\text { Up to primary } \\
\text { school }\end{array}$ & 194 & $5(2.6)$ & $1.26(0.38-4.18)$ & 0.709 \\
\hline $\begin{array}{c}\text { Middle school } \\
\text { and above }\end{array}$ & 291 & $6(2.1)$ & 1 & \\
\hline \multicolumn{5}{|l|}{ Occupation } \\
\hline Forest-related & 239 & $10(4.2)$ & $10.69(1.36-84.24)$ & $0.005^{* *}$ \\
\hline $\begin{array}{l}\text { Non-forest- } \\
\text { related }\end{array}$ & 246 & $1(0.4)$ & 1 & \\
\hline \multicolumn{5}{|l|}{ Family size } \\
\hline $\begin{array}{l}\text { Less than } 3 \\
\text { people }\end{array}$ & 108 & $3(2.8)$ & $1.32(0.34-5.06)$ & 0.687 \\
\hline 3 people or more & 377 & $8(2.1)$ & 1 & \\
\hline \multicolumn{5}{|l|}{ Use of bed net } \\
\hline Yes & 481 & $11(2.3)$ & - & 0.76 \\
\hline No & 4 & $0(0)$ & & \\
\hline \multicolumn{5}{|c|}{ Type of bed nets ( $n=481$ ) } \\
\hline $\begin{array}{l}\text { Ordinary bed } \\
\text { nets }\end{array}$ & 395 & $9(2.3)$ & $1.21(0.26-5.53)$ & 0.979 \\
\hline $\begin{array}{l}\text { Insecticide- } \\
\text { treated bed } \\
\text { nets }\end{array}$ & 86 & $2(2.3)$ & 1 & \\
\hline
\end{tabular}

* $P$ value by $C h i$ square test

** Significant at $P<0.05$ 


\section{Discussion}

Most countries in the GMS, including Myanmar, are currently at the pre-elimination phase of malaria. Timely identification and prompt treatment of symptomatic malaria infections, as well as detection of asymptomatic individuals and treatment of malaria reservoirs, are deemed essential for eliminating the source of disease transmission. Information about the epidemiology of asymptomatic malaria infection in Myanmar is sparse. This study provided additional data on the prevalence of asymptomatic malaria infections in Kayah State, eastern Myanmar.

Microscopy is currently the gold standard for malaria diagnosis among symptomatic patients. However, lowdensity infections especially among asymptomatic parasite carriers, are easily missed by microscopy diagnosis because parasite densities are often below the detection limit of microscopes (normally above 50 parasites/ $\mu \mathrm{l}$ of blood) [24-27]. In this study, individuals with low parasitaemia were more likely to be missed by the local microscopist. Several studies have indicated that low-density infections are more easily missed by light microscopy [12, $16,17]$. Similar discrepancies in malaria diagnosis have been reported for recent studies conducted in the same region as in this study $[11,17]$.

Because of generally lower parasitaemia in asymptomatic infections, a more sensitive test is critical for identifying asymptomatic carriers. Using PCR, asymptomatic $P$. falciparum and $P$. vivax infections were identified. The prevalence was similar to the values $(1.9 \%)$ found in a previous study conducted in Mae Hong Son, Thailand, which was also determined by PCR [13]. The result of the current study was also within the range of asymptomatic malaria infection in Myanmar, which has been reported to be $1.0-9.4 \%$ in southern areas [16]. Plasmodium vivax was the most prevalent species among asymptomatic cases in this study, similar to the distribution of malaria species reported in other works $[11,12]$. However, a recent study in central Myanmar reported the low prevalence of asymptomatic malaria infection, with a predominance of $P$. falciparum [28]. The difference likely reflects the heterogeneity of malaria species distribution in central Myanmar.

Age is considered one of the most important factors that correlate with protective immunity in malariaendemic areas [9]. Young children are generally the most vulnerable to developing the disease. However, adults and older children who might have had several episodes of malaria and have acquired immunity are more likely to harbor asymptomatic infection $[29,30]$. This study found that all asymptomatic infections were restricted to participants aged $>17$ years. Probably due to the low overall prevalence $(2.3 \%)$ and the small number of children enrolled in this study, the difference in infection rates between adults and children did not reach statistical significance [7]. That only adults were infected suggests that these infections were more likely transmitted outside of residential areas, consistent with forest-related activities being a strong risk factor. Entomological data for local vectors would be helpful in establishing the most likely areas of active transmission. This finding is also consistent with the lack of association of malaria infections with the use of bed nets.

Many previous studies have found that males are more likely to have Plasmodium infections than females [14, 31-33]. In this study, men working in the forests had much higher infection rates. Because men tend to engage in more agricultural and forest-related activities, such as wood and bamboo cutting as similarly reported in another study [34], the risk was most likely occupational. When occupational risk factors had been taking into account, the difference in infection rates between male and female was no longer statistically significant.

This work is among a very few studies $[4,16]$ reporting the current situation of malaria in Myanmar, whose mountainous terrain limits access to local communities in many areas. This cross-sectional study was conducted in June, and thus the seasonal pattern of asymptomatic malaria infection cannot be assessed. However, the available data clearly indicate that the study areas are currently at the low end of endemicity. These data provide justification for investing resources to target male forest workers, so as to interrupt malaria transmission.

\section{Conclusion}

A combination of RDT, light microscopy and PCR diagnostics was used to identify asymptomatic malaria infections. Risk factors were identified to improve malaria risk stratification and to guide decision-makers towards better design and delivery of targeted interventions in small villages, representative of Kayah State. In addition to the routine statistics on symptomatic cases, information on asymptomatic cases is useful for determining the true burden of disease in the area. Further studies, including entomological aspects, genotyping of asexual and sexual parasites, and immune system evaluation, are needed to better understand the epidemiology of asymptomatic Plasmodium spp. infections and their contribution to the dynamics of malaria transmission and to the incidence of symptomatic infections.

\footnotetext{
Authors' contributions

MTZ, WN, JK, LC, and JS were involved in the design of the study. MT, KP, KP, TS, and RY performed the laboratory experiments and analysis. MTZ, NZA and MT were involved in sample collection. TMH took care of the administrative work for the data collection and IF developed Plasmodium knowlesi qPCR assay. MTZ, WN and JK did the statistical analysis, and MTZ wrote the original draft. All authors read and provided comments, suggestions and edits of the draft. All authors read and approved the final manuscript.
} 


\begin{abstract}
Author details
1 Defence Services Medical Research Centre (DSMRC), Nay Pyi Taw, Myanmar.

${ }^{2}$ Loikaw Military Hospital, Loikaw, Kayah, Myanmar. ${ }^{3}$ Mahidol Vivax Research Unit (MVRU), Faculty of Tropical Medicine, Mahidol University, Bangkok, Thailand. ${ }^{4}$ Department of Molecular Tropical Medicine and Genetics, Faculty of Tropical Medicine, Mahidol University, Bangkok, Thailand. ${ }^{5}$ Department of Medical Parasitology and Infection Biology, Swiss Tropical \& Public Health Institute, Basel, Switzerland. ${ }^{6}$ Department of Tropical Hygiene, Faculty of Tropical Medicine, Mahidol University, Bangkok, Thailand. ${ }^{7}$ Department of Entomology, The Pennsylvania State University, 501 ASI Building, University Park, PA 16801, USA.
\end{abstract}

\section{Acknowledgements}

We would like to thank NIH for supporting this study. MTZ and RY are both supported by NIH D43 grants. We would like to acknowledge all the individuals who participated in this study. We are very grateful to the Chief Commanding Officer and his team at Loikaw Hospital, Kayah State for their assistance and collaboration during the planning of the survey.

\section{Competing interests}

The authors declare that they have no competing interests.

\section{Availability of data and materials}

The datasets used and/or analysed during the current study is available from the corresponding authors on request.

\section{Ethics approval and consent to participant}

This study was approved by the Institutional Review Board of the Faculty of Tropical Medicine, Mahidol University (MUTM 2016-0140-01) and the Defence Services Medical Research Centre (DSMRC), Myanmar (IRB/2016/31). Written informed consent was obtained from all adults willing to participate in the study, and a parent provided consent for participants less than 18 years of age.

\section{Funding}

This study was supported by Grants (D43TW006571 and U19AI089672) from the National Institutes of Health (NIH), USA.

Received: 6 February 2017 Accepted: 22 March 2017

Published online: 04 April 2017

\section{References}

1. MOH. Health in Myanmar 2014. Nay Pyi Taw: Ministry of Health; 2014.

2. Cui L, Yan G, Sattabongkot J, Cao Y, Chen B, Chen X, et al. Malaria in the Greater Mekong Subregion: heterogeneity and complexity. Acta Trop. 2012;121:227-39.

3. WHO. World malaria report 2015. Geneva: World Health Organization; 2015.

4. Mu TT, Sein AA, Kyi TT, Min M, Aung NM, Anstey NM, et al. Malaria incidence in Myanmar 2005-2014: steady but fragile progress towards elimination. Malar J. 2016;15:503.

5. Alves FP, Gil LH, Marrelli MT, Ribolla PE, Camargo EP, Da Silva LH. Asymptomatic carriers of Plasmodium spp. as infection source for malaria vector mosquitoes in the Brazilian Amazon. J Med Entomol. 2005;42:777-9.

6. Zoghi S, Mehrizi AA, Raeisi A, Haghdoost AA, Turki H, Safari R, et al. Survey for asymptomatic malaria cases in low transmission settings of Iran under elimination programme. Malar J. 2012;11:126.

7. Lindblade KA, Steinhardt L, Samuels A, Kachur SP, Slutsker L. The silent threat: asymptomatic parasitemia and malaria transmission. Expert Rev Anti Infect Ther. 2013;11:623-39.

8. Stresman GH, Baidjoe AY, Stevenson J, Grignard L, Odongo W, Owaga C, et al. Focal screening to identify the subpatent parasite reservoir in an area of low and heterogeneous transmission in the Kenya highlands. J Infect Dis. 2015;212:1768-77.

9. Laishram DD, Sutton PL, Nanda N, Sharma VL, Sobti RC, Carlton JM, et al. The complexities of malaria disease manifestations with a focus on asymptomatic malaria. Malar J. 2012;11:29.

10. Alves FP, Durlacher RR, Menezes MJ, Krieger H, Silva LH, Camargo EP. High prevalence of asymptomatic Plasmodium vivax and Plasmodium falciparum infections in native Amazonian populations. Am J Trop Med Hyg. 2002;66:641-8.

11. Baum E, Sattabongkot J, Sirichaisinthop J, Kiattibutr K, Davies DH, Jain A, et al. Submicroscopic and asymptomatic Plasmodium falciparum and Plasmodium vivax infections are common in western Thailand-molecular and serological evidence. Malar J. 2015;14:95.

12. Coleman RE, Sattabongkot J, Promstaporm S, Maneechai N, Tippayachai B, Kengluecha A, et al. Comparison of PCR and microscopy for the detection of asymptomatic malaria in a Plasmodium falciparum/vivax endemic area in Thailand. Malar J. 2006;5:121.

13. Congpuong K, Saejeng A, Sug-Aram R, Aruncharus S, Darakapong A, Meshnick SR, et al. Mass blood survey for malaria: pooling and real-time PCR combined with expert microscopy in north-west Thailand. Malar J. 2012;11:288.

14. Imwong M, Nguyen TN, Tripura R, Peto TJ, Lee SJ, Lwin KM, et al. The epidemiology of subclinical malaria infections in South-East Asia: findings from cross-sectional surveys in Thailand-Myanmar border areas, Cambodia, and Vietnam. Malar J. 2015;14:381.

15. Kritsiriwuthinan K, Ngrenngarmlert W. Molecular screening of Plasmodium infections among migrant workers in Thailand. J Vector Borne Dis. 2011;48:214-8.

16. Wang B, Han S-S, Cho C, Han J-H, Cheng Y, Lee S-K, et al. Comparison of microscopy, nested-PCR, and real-time-PCR assays using high-throughput screening of pooled samples for diagnosis of malaria in asymptomatic carriers from areas of endemicity in Myanmar. J Clin Microbiol. 2014:52:1838-45.

17. Parker DM, Matthews SA, Yan G, Zhou G, Lee MC, Sirichaisinthop J, et al. Microgeography and molecular epidemiology of malaria at the ThailandMyanmar border in the malaria pre-elimination phase. Malar J. 2015;14:198.

18. Sturrock HJ, Hsiang MS, Cohen JM, Smith DL, Greenhouse B, Bousema $T$, et al. Targeting asymptomatic malaria infections: active surveillance in control and elimination. PLoS Med. 2013;10:e1001467.

19. Programme National Malaria Control. Malaria annual report 2013. Nay Pyi Taw: National Malaria Control Programme; 2013.

20. WHO. Malaria rapid diagnostic test performance: results of WHO product testing of malaria RDTs: round 6 (2014-2015). Geneva: World Health Organization; 2015.

21. Wampfler R, Mwingira F, Javati S, Robinson L, Betuela I, Siba P, et al. Strategies for detection of Plasmodium species gametocytes. PLOS ONE. 2013;8:e76316.

22. Rosanas-Urgell A, Mueller D, Betuela I, Barnadas C, Iga J, Zimmerman PA, et al. Comparison of diagnostic methods for the detection and quantification of the four sympatric Plasmodium species in field samples from Papua New Guinea. Malar J. 2010;9:361.

23. Hofmann N, Mwingira F, Shekalaghe S, Robinson LJ, Mueller I, Felger I. Ultra-sensitive detection of Plasmodium falciparum by amplification of multi-copy subtelomeric targets. PLoS Med. 2015;12:e1001788.

24. Ouedraogo AL, Bousema T, Schneider P, de Vlas SJ, Ilboudo-Sanogo E, Cuzin-Ouattara N, et al. Substantial contribution of submicroscopical Plasmodium falciparum gametocyte carriage to the infectious reservoir in an area of seasonal transmission. PLoS ONE. 2009;4:e8410.

25. Harris I, Sharrock WW, Bain LM, Gray KA, Bobogare A, Boaz L, et al. A large proportion of asymptomatic Plasmodium infections with low and sub-microscopic parasite densities in the low transmission setting of Temotu Province, Solomon Islands: challenges for malaria diagnostics in an elimination setting. Malar J. 2010;9:254.

26. Steenkeste N, Rogers WO, Okell L, Jeanne I, Incardona S, Duval L, et al. Sub-microscopic malaria cases and mixed malaria infection in a remote area of high malaria endemicity in Rattanakiri province, Cambodia: implication for malaria elimination. Malar J. 2010;9:108.

27. Okell LC, Bousema T, Griffin JT, Ouedraogo AL, Ghani AC, Drakeley CJ. Factors determining the occurrence of submicroscopic malaria infections and their relevance for control. Nat Commun. 2012;3:1237.

28. Ghinai I, Cook J, Hla TT, Htet HM, Hall T, Lubis IN, et al. Malaria epidemiology in central Myanmar: identification of a multi-species asymptomatic reservoir of infection. Malar J. 2017;16:16.

29. Doolan DL, Dobano C, Baird JK. Acquired immunity to malaria. Clin Microbiol Rev. 2009;22:13-36.

30. Djimde AA, Doumbo OK, Traore O, Guindo AB, Kayentao K, Diourte Y, et al. Clearance of drug-resistant parasites as a model for protective immunity in Plasmodium falciparum malaria. Am J Trop Med Hyg. 2003;69:558-63. 
31. Li N, Parker DM, Yang Z, Fan Q, Zhou G, Ai G, et al. Risk factors associated with slide positivity among febrile patients in a conflict zone of northeastern Myanmar along the China-Myanmar border. Malar J. 2013;12:361.

32. Wang RB, Zhang J, Zhang QF. Malaria baseline survey in four special regions of northern Myanmar near China: a cross-sectional study. Malar J. 2014;13:302.

33. Bassa FK, Ouattara M, Silue KD, Adiossan LG, Baikoro N, Kone S, et al. Epidemiology of malaria in the Taabo health and demographic surveillance system, south-central Cote d'Ivoire. Malar J. 2016;15:9.
34. Cucunuba ZM, Guerra AP, Rahirant SJ, Rivera JA, Cortes LJ, Nicholls RS Asymptomatic Plasmodium spp. infection in Tierralta, Colombia. Mem Inst Oswaldo Cruz. 2008;103:668-73.

\section{Submit your next manuscript to BioMed Central and we will help you at every step:}

- We accept pre-submission inquiries

- Our selector tool helps you to find the most relevant journal

- We provide round the clock customer support

- Convenient online submission

- Thorough peer review

- Inclusion in PubMed and all major indexing services

- Maximum visibility for your research

Submit your manuscript at

www.biomedcentral.com/submit 